\title{
ANALISIS PENGARUH TINGKAT KEBISINGAN PADA STASIUN STERILIZER TERHADAP KUALITAS TIDUR OPERATOR
}

\author{
Faradila Ananda Yul, Dedi Dermawan, Fira Aldiyanti \\ Program Studi Teknik Industri, Fakultas Teknik, Universitas Muhammadiyah Riau \\ Jalan Tuanku Tambusai Ujung, Kecamatan Tampan, Kelurahan Delima, Kota Pekanbaru, Riau 28291 \\ Email: faradila@umri.ac.id
}

\begin{abstract}
Palm Oil Mill PT. Surya Intisari Raya, Sei Lukut is a plantation company engaged in the commodity palm oil FFB (Fresh Fruit Bunches), with output in the form of CPO (Crude Palm Oil) and Palm Kernel (PK). There are 13 processing stations at PKS that have high noise levels, one of which is a sterilizer station which can disrupt operator psychology, namely Sleep Disturbance. In the field survey, it was found that operators experienced concentration problems such as drowsiness, and not all of them used ear protection in the form of earplugs/earmuffs. Therefore, it is necessary to identify the noise level at the sterilizer station and to analyze its effect on the operator's sleep quality using an observational analytic cross-sectional approach. Noise in the workplace was measured using a sound level meter and the sleep quality of workers was measured using the Pittsburgh Sleep Quality Index (PSQI) questionnaire. Based on the results of noise level measurements, 4 processes have noise above the Threshold Limit Value, namely Deaeration of 89.824 $d B$, Containment of $92.548 d B$, Peak BlowDown by 2 of 96.45 dB, and Final of $102.77 \mathrm{~dB}$. Based on the results of the Pittsburgh Sleep Quality Index (PSQI) questionnaire, 100\% of Morning Shift and Night Shift workers have poor sleep quality. To overcome this problem, several suggestions were made, namely to carry out periodic health checks for operators, ensure that operators who are exposed to noise always wear an earplug/earmuff, and minimize exposure to noise above the NAB to operators by keeping noise points away from the operator's premises.
\end{abstract}

Keywords: Noises, Sleep Quality, Worker

\begin{abstract}
Abstrak
Pabrik Kelapa Sawit PT. Surya Intisari Raya, Sei Lukut merupakan perusahaan perkebunan yang bergerak di bidang komoditi kelapa sawit TBS (Tandan Buah Segar), dengan hasil output berupa CPO (Crude Palm Oil) dan Palm Kernel (PK). Terdapat 13 stasiun pengolahan pada PKS yang memiliki tingkat kebisingan tinggi, salah satunya adalah stasiun sterilizer yang dapat menyebabkan terganggunya psikologi operator yaitu gangguan pola tidur. Dalam survey lapangan ditemukan bahwa operator mengalami gangguan konsentrasi seperti mengantuk dan tidak semua menggunakan alat pelindung telinga berupa earplug/earmuff. Maka dari itu dilakukan tindakan identifikasi terhadap tingkat kebisingan pada stasiun sterilizer dan analisis pengaruhnya terhadap kualitas tidur operator menggunakan analitik observasional dengan pendekatan cross sectional. Kebisingan ditempat kerja diukur menggunakan sound level meter dan kualitas tidur pekerja diukur dengan kuesioner Pittssburgh Sleep Quality Index (PSQI). Berdasarkan hasil pengukuran tingkat kebisingan terdapat 4 proses yang memiliki kebisingan diatas Nilai Ambang Batas (NAB) yaitu Deaerasi sebesar 89,824 dB, Penahanan sebesar 92,548 dB, BlowDown Puncak 2 sebesar 96,45 dB dan Final sebesar 102,77 dB. Berdasarkan hasil kuesioner Pittssburgh Sleep Quality Index (PSQI), 100\% pekerja Shift Pagi dan Shift Malam memiliki kualitas tidur yang buruk. Untuk mengatasi masalah tersebut diberikan beberapa usulan yaitu melakukan pengecekan kesehatan secara berkala bagi operator, memastikan bahwa operator yang terpapar kebisingan selalu memakai earplug/earmuff, dan meminimalkan terpaparnya kebisingan diatas $\mathrm{NAB}$ terhadap operator dengan menjauhkan titik kebisingan dari tempat operator.
\end{abstract}

Kata Kunci: Kebisingan, Kualitas Tidur, Pekerja Pabrik

1. Pendahuluan

Pabrik Kelapa Sawit (PKS) PT. Surya Intisari Raya (SIR) Kebun Sei Lukut merupakan perusahaan perkebunan yang bergerak di bidang komoditi kelapa sawit TBS (Tandan Buah Segar), dengan hasil output berupa CPO (Crude Palm Oil) dan Palm Kernel (PK). Terdapat 13 stasiun kerja dalam sebuah PKS, masing-masing

SURYA TEKNIKA Vol. 7 No. 2, Desember 2020: 186-191 
stasiun memiliki kebisingan yang tinggi. Kebisingan tertinggi terletak pada stasiun kernel sebesar 99,55 dB dan kebisingan terendah terletak pada stasiun storage tank sebesar 65,7 dB.

Berikut adalah diagram tingkat kebisingan dari setiap stasiun.

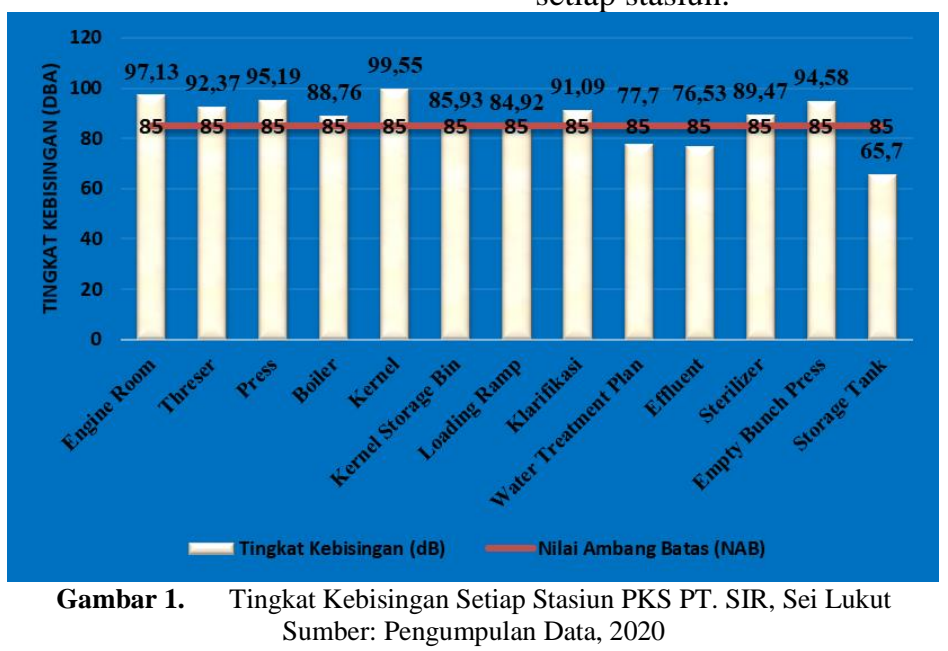

Sterilizer merupakan salah satu stasiun yang memiliki kebisingan cukup tinggi yaitu sebesar 89,47 dB. Stasiun sterilizer berfungsi sebagai tempat proses perebusan TBS dengan menggunakan panas dari uap yang bertekanan tinggi secara konveksi dan konduksi (Faizal AA, 2007). Pada stasiun sterilizer operator bekerja selama 7 s/d 8 jam setiap satu shift kerja yang mengakibatkan resiko seringnya terpapar kebisingan yang tinggi. Sumber kebisingan yang dihasilkan dari sterilizer adalah ketika terjadinya proses Deaerasi, BlowDown Condensate, puncak setiap perebusan, proses Penahanan dan proses Final setiap perebusan.

Kebisingan adalah semua suara yang tidak dikehendaki yang bersumber dari alat-alat proses produksi dan/atau alat-alat kerja yang pada tingkat tertentu dapat menimbulkan gangguan pendengaran (Peraturan Menteri Tenaga Kerja dan Transmigrasi Nomor 13, 2011). Nilai Ambang Batas (NAB) kebisingan adalah 85 dB(A), diatur oleh Menteri Tenaga Kerja Nomor KEP. 13/Men/X/2011. Pengambilan data dilakukan menggunakan alat sound level meter DT-8820 dengan menggunakan satuan $\mathrm{dB}(\mathrm{A})$, $\mathrm{dB}(\mathrm{A})$ digunakan untuk penilaian kepekaan telinga manusia, sedangkan $\mathrm{dB}(\mathrm{C})$ digunakan untuk pengontrolan suatu sumber bunyi (mengetahui kerusakan mesin) pada level yang tinggi.

Dalam proses wawancara operator mengatakan bahwa kebisingan yang terjadi sangat berpangaruh mengganggu konsentrasi hingga kelelahan sehingga mengakibatkan rasa kantuk yang berat. Bising menyebabkan berbagai gangguan terhadap tenaga kerja, seperti gangguan fisiologis, gangguan psikologis, gangguan komunikasi dan ketulian, atau ada yang menggolongkan gangguannya berupa gangguan auditory, misalnya gangguan terhadap pendengaran dan gangguan non auditory seperti komunikasi terganggu, ancaman bahaya keselamatan, menurunnya performance kerja, kelelahan dan stress (Buchari, 2007).

Sebuah penelitian kecil yang dilakukan di Taiwan dilaporkan dalam jurnal Sleep telah menunjukkan bahwa terpapar di tempat kerja yang bising sepanjang hari dapat menyebabkan stress. Stress tersebut akan terbawa ke malam hari dan mengurangi kualitas tidur. Para peneliti menemukan bahwa ketika para pekerja mendapatkan paparan kebisingan kerja lebih tinggi, mereka memiliki tekanan darah yang lebih tinggi dan kadar hormon-hormon kortisol juga jauh lebih tinggi. Hormon kortisol adalah hormon yang berkaitan dengan respons tubuh terhadap stress dan dihasilkan oleh kelenjar adrenal. Hormon kortisol diperlukan tubuh saat menghadapi mekanisme fight of flight response, ketika tubuh menghadapi tantangan secara mental maupun fisik.

Kebisingan yang terjadi pada stasiun sterilizer dapat berpengaruh pada operator dari segi psikologi yaitu gangguan pola tidur. Tujuan dari penelitian ini adalah untuk mengetahui hubungan antara kebisingan di tempat kerja dengan kualitas tidur operator pada stasiun sterilizer di PT. SIR, Sei Lukut.

\section{Metodologi}

Jenis penelitian ini adalah analitik observasional dengan desain penelitian cross sectional. 
Penelitian dilaksanakan di Pabrik Kelapa Sawit (PKS) PT. Surya Intisari Raya (SIR), Sei Lukut pada bulan Agustus 2020.

Responden penelitian adalah pekerja pada stasiun sterilizer PKS PT. SIR, Sei Lukut Data intensitas kebisingan diperoleh dengan mengukur di tempat kerja menggunakan alat sound level meter. Data kualitas tidur pekerja diperoleh dari pengisian kuesioner Pittssburgh Sleep Quality Index (PSQI). Data karakteristik sampel diperoleh dari pengisian lembar identitas oleh pekerja. berdasarkan kriteria inklusi: (1) pekerja Shift Pagi dan Shift Malam, (2) diizinkan oleh pihak perusahaan untuk menjadi subyek penelitian, (3) bersedia menjadi subyek penelitian, (4) berusia 20-68 tahun, (5) berjenis kelamin laki-laki.

\section{Hasil dan Pembahasan}

Peneliti melakukan pengukuran dan identifikasi tingkat kebisingan pada satu siklus perebusan stasiun sterilizer di PKS PT. SIR, Sei Lukut. Hasil pengukuran dapat dilihat pada Tabel 1.

Tabel 1.Tingkat Kebisingan Stasiun Sterilizer

\begin{tabular}{|c|l|c|c|l|}
\hline No & \multicolumn{1}{|c|}{$\begin{array}{c}\text { Titik Pengukuran (Setiap } \\
\text { Proses) }\end{array}$} & Tingkat Kebisingan (dB) & NAB Kebisingan (dB) & Keterangan \\
\hline 1 & Deaerasi & 89,824 & 85 & Diatas NAB \\
\hline 2 & Puncak 1 & 84,308 & 85 & Dibawah NAB \\
\hline 3 & Puncak 2 & 83,668 & 85 & Dibawah NAB \\
\hline 4 & Puncak 3 & 84,22 & 85 & Dibawah NAB \\
\hline 5 & Penahanan & 92,548 & 85 & Diatas NAB \\
\hline 6 & BD Puncak 1 & 81,98 & 85 & Dibawah NAB \\
\hline 7 & BD Puncak 2 & 96,45 & 85 & Diatas NAB \\
\hline 8 & Final & 102,77 & 85 & Diatas NAB \\
\hline
\end{tabular}

Sumber: Pengolahan Data, 2020

Berdasarkan Tabel 1. terdapat empat proses yang memiliki kebisingan diatas Nilai Ambang Batas (NAB) yaitu proses Deaerasi sebesar 89,824 dB, proses Penahanan sebesar 92,548 dB, proses BlowDown Puncak 2 sebesar 96,45 dB, dan proses Final sebesar 102,77 dB.
Berdasarkan Gambar 2. diketahui bahwa $25 \%$ usia pekerja stasiun sterilizer memiliki rentang usia 21-35 Tahun, sedang 75\% pekerja memiliki rentang usia 36-45 Tahun. Pada Gambar 3. juga diketahui bahwa $25 \%$ pekerja memiliki lama masa bekerja 11-20 Tahun, sedangkan 75\% pekerja memiliki masa lama bekerja 1-10 Tahun.

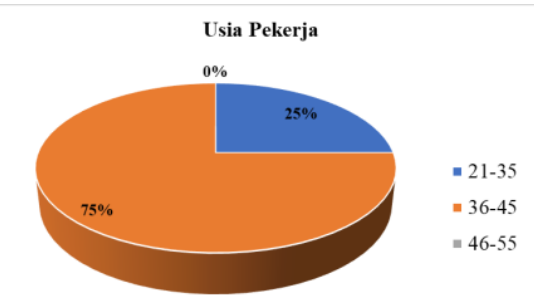

Gambar 2. Usia Pekerja Stasiun Sterilizer PKS PT. SIR, Sei Lukut Sumber: Pengolahan Data, 2020

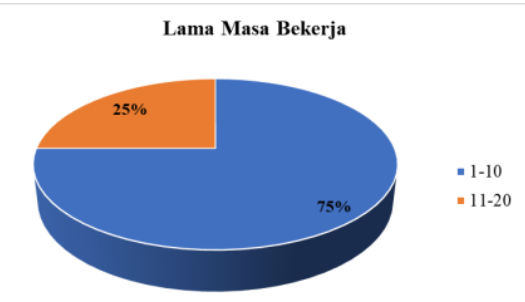

Gambar 3. Lama Stasiun Sterilizer PKS PT. SIR, Sei Lukut Sumber: Pengolahan Data, 2020

Berdasarkan hasil pengolahan data kuesioner PSQI Shift Pagi pada Tabel 2. Dan Tabel 3., dapat disimpulkan bahwa $100 \%$ pekerja Shift Pagi dan
Shift Malam mengalami gangguan kualitas tidur yang buruk dengan total skor menunjukkan $>5$ dalam skala ordinal.

SURYA TEKNIKA Vol. 7 No. 2, Desember 2020: 186-191 
Tabel 2.Distribusi Skor PSQI Shift Pagi

\begin{tabular}{|c|c|c|c|c|}
\hline No & Komponen & Kategori & Frekuensi (n) & Persentase (\%) \\
\hline \multirow{4}{*}{1} & \multirow{4}{*}{ Kualitas Tidur Subyektif } & Baik Sekali & 0 & 0 \\
\hline & & Baik & 1 & 25 \\
\hline & & Buruk & 3 & 75 \\
\hline & & Buruk Sekali & 0 & 0 \\
\hline \multirow{4}{*}{2} & \multirow{4}{*}{ Latensi Tidur } & 0 & 1 & 25 \\
\hline & & 1 & 0 & 0 \\
\hline & & 2 & 1 & 25 \\
\hline & & 3 & 2 & 50 \\
\hline \multirow{4}{*}{3} & \multirow{4}{*}{ Durasi Tidur } & $>7$ & 0 & 0 \\
\hline & & $6-7$ & 0 & 0 \\
\hline & & $5-6$ & 4 & 100 \\
\hline & & $<5$ & 0 & 0 \\
\hline \multirow{4}{*}{4} & \multirow{4}{*}{ Efisiensi Tidur } & $>85$ & 0 & 0 \\
\hline & & $75-84$ & 1 & 25 \\
\hline & & $65-74$ & 3 & 75 \\
\hline & & $<65$ & 0 & 0 \\
\hline \multirow{4}{*}{5} & \multirow{4}{*}{ Gangguan Tidur } & 0 & 0 & 0 \\
\hline & & 1 & 2 & 50 \\
\hline & & 2 & 2 & 50 \\
\hline & & 3 & 0 & 0 \\
\hline \multirow{4}{*}{6} & \multirow{4}{*}{ Penggunaan Obat Tidur } & Tidak Pernah & 4 & 100 \\
\hline & & $<1$ Kali/Minggu & 0 & 0 \\
\hline & & 1-2 Kali/Minggu & 0 & 0 \\
\hline & & $\geq 3$ Kali/Seminggu & 0 & 0 \\
\hline \multirow{4}{*}{7} & \multirow{4}{*}{ Disfungsi Aktivitas Siang Hari } & 0 & 0 & 0 \\
\hline & & 1 & 2 & 50 \\
\hline & & 2 & 0 & 0 \\
\hline & & 3 & 2 & 50 \\
\hline \multirow{2}{*}{8} & \multirow{2}{*}{ Total } & $\leq 5$ & 0 & 0 \\
\hline & & $>5$ & 4 & 100 \\
\hline
\end{tabular}

Sumber: Pengolahan Data, 2020

\begin{tabular}{|c|c|c|c|c|}
\hline No & Komponen & Kategori & Frekuensi (n) & Persentase (\%) \\
\hline \multirow{4}{*}{1} & \multirow{4}{*}{ Kualitas Tidur Subyektif } & Baik Sekali & 0 & 0 \\
\hline & & Baik & 0 & 0 \\
\hline & & Buruk & 4 & 100 \\
\hline & & Buruk Sekali & 0 & 0 \\
\hline \multirow{4}{*}{2} & \multirow{4}{*}{ Latensi Tidur } & 0 & 1 & 25 \\
\hline & & 1 & 1 & 25 \\
\hline & & 2 & 0 & 0 \\
\hline & & 3 & 2 & 50 \\
\hline \multirow{4}{*}{3} & \multirow{4}{*}{ Durasi Tidur (Jam) } & $>7$ & 0 & 0 \\
\hline & & $6-7$ & 0 & 0 \\
\hline & & $5-6$ & 4 & 100 \\
\hline & & $<5$ & 0 & 0 \\
\hline \multirow{4}{*}{4} & \multirow{4}{*}{ Efisiensi Tidur (\%) } & $>85$ & 3 & 75 \\
\hline & & $75-84$ & 1 & 25 \\
\hline & & $65-74$ & 0 & 0 \\
\hline & & $<65$ & 0 & 0 \\
\hline \multirow{4}{*}{5} & \multirow{4}{*}{ Gangguan Tidur } & 0 & 0 & 0 \\
\hline & & 1 & 3 & 75 \\
\hline & & 2 & 1 & 25 \\
\hline & & 3 & 0 & 0 \\
\hline \multirow{4}{*}{6} & \multirow{4}{*}{ Penggunaan Obat Tidur } & Tidak Pernah & 4 & 100 \\
\hline & & $<1 \mathrm{Kali} /$ Minggu & 0 & 0 \\
\hline & & 1-2 Kali/Minggu & 0 & 0 \\
\hline & & $\geq 3 \mathrm{Kali} /$ Seminggu & 0 & 0 \\
\hline \multirow{4}{*}{7} & \multirow{4}{*}{ Disfungsi Aktivitas Malam Hari } & 0 & 0 & 0 \\
\hline & & 1 & 0 & 0 \\
\hline & & 2 & 2 & 50 \\
\hline & & 3 & 2 & 50 \\
\hline \multirow{2}{*}{8} & \multirow{2}{*}{ Total } & $\leq 5$ & 0 & 0 \\
\hline & & $>5$ & 4 & 100 \\
\hline
\end{tabular}

Sumber: Pengolahan Data, 2020

SURYA TEKNIKA Vol. 7 No. 2, Desember 2020: 186-191 
Berdasarkan lamanya waktu pemaparan kebisingan yang diterima pekerja setelah dilakukan perhitungan dengan rumus $\mathrm{NIOSH}$ maka dihasilkan waktu maksimal yang diperbolehkan bagi pekerja untuk terpapar kebisingan. Para pekerja diperbolehkan terpapar secara langsung selama batas waktu yang telah ditentukan. Jika bekerja melebihi batas waktu yang ditentukan sebaiknya menggunakan alat pelindung telinga.

Berikut adalah waktu lama pemaparan kebisingan yang diizinkan setiap proses pada stasiun sterilizer.

Tabel 4.Distribusi Skor PSQI Shift Malam

\begin{tabular}{|c|l|c|c|}
\hline No & TiTik Pengukuran (Setiap Proses) & Tingkat Kebisingan (dB) & Lama Pemaparan (Jam) \\
\hline 1 & Deaerasi & 89,824 & 2,62 \\
\hline 2 & Puncak 1 & 84,308 & 9,41 \\
\hline 3 & Puncak 2 & 83,668 & 10,94 \\
\hline 4 & Puncak 3 & 84,22 & 9,57 \\
\hline 5 & Penahanan & 92,548 & 1,39 \\
\hline 6 & BlowDown Puncak 1 & 81,98 & 16,06 \\
\hline 7 & BlowDown Puncak 2 & 96,45 & 0,57 \\
\hline 8 & Final & 102,77 & 0,13 \\
\hline
\end{tabular}

Sumber: Pengolahan Data, 2020

Manusia dewasa dalam rentang usia 26-64 tahun membutuhkan waktu tidur 7-9 jam/hari dan hanya boleh terpapar kebisingan sebesar $85 \mathrm{~dB}$ selama 8 jam/hari, kurangnya waktu tidur dan terlalu sering terpapar kebisingan yang tinggi secara terus menerus mengakibatkan meningkatnya hormon-hormon kortisol pada manusia sehingga dapat menyebabkan gangguan secara psikologi seperti stress hingga gangguan pola tidur. Pada PKS PT. SIR, Sei Lukut, pekerja pada stasiun sterilizer hanya memiliki waktu efektif tidur 5-6 jam/hari dan terpapar kebisingan diatas NAB selama 7-8 jam/hari dalam masa bekerja 3 bulan- 20 tahun.

Berdasarkan hasil pengolahan data kuesioner Pittssburgh Sleep Quality Index (PSQI) untuk pekerja shift pagi dan shift malam pada stasiun sterilizer menunjukkan bahwa $100 \%$ pekerja mengalami gangguan kualitas tidur yang buruk. Berdasarkan hasil perhitungan paparan kebisingan pada stasiun sterilizer, dari 8 proses yang ada dalam satu siklus perebusan menunjukkan 4 proses yang memiliki nilai kebisingan diatas NAB yaitu proses Deaerasi sebesar 89,824 dB, proses Penahanan sebesar 92,548 dB, proses BlowDown Puncak 2 sebesar 96,45 dB, dan proses Final sebesar 102,77 dB.

Penyebab tingginya kebisingan pada proses diatas adalah akibat dari tekanan steam yang tinggi dari stasiun engine room menuju sterilizer untuk memenuhi standar kebutuhan perebusan TBS agar menghasilkan output maksimal sesuai dengan yang diharapkan.

Dalam survey lapangan ditemukan bahwa sebagian pekerja tidak menerapkan penggunaan K3 seperti earplug/earmuff sehingga beresiko terpapar langsung oleh kebisingan diatas NAB.
Dalam proses wawancara juga didapati bahwa tidak semua operator rutin mengikuti pengecekkan kesehatan secara berkala yang sudah ditentukan perusahaan.

Dari hasil survey dan observasi lapangan yang telah dilakukan maka dapat disimpulkan bahwa terpapar kebisingan pada stasiun sterilizer memiliki pengaruh buruk terhadap kualitas tidur operator.

\section{Simpulan}

Berdasarkan hasil penelitian, dapat disimpulkan bahwa terdapat empat proses dalam siklus perebusan yang memiliki tingkat kebisingan diatas NAB yaitu Deaerasi, Penahanan, BlowDown Puncak 2 dan Final. Terpapar kebisingan dalam kurun waktu kerja 7-8 Jam/Hari secara terus menerus mengakibatkan meningkatknya hormone kortisol pada pekerja sehingga menyebabkan terganggunya kualitas tidur pekerja.

\section{Daftar Pustaka}

[1] Anizar, 2012. Teknik Keselamatan dan Kesehatan Kerja di Industri. Yogyakarta: Graha Ilmu. World Health Organization (WHO). 2015. Deafness and Hearing Loss. Fact sheet Number 300. Revisi Maret 2015.

[2] Buysse, D. J., et al. (1989). "The Pittsburgh Sleep Quality Index: a new instrument for psychiatric practice and research." Psychiatry research 28(2): 193-213.

[3] Gitanjali, B. dan R. Dhamodharan. 2004. Effect of occupational noise on the nocturnal sleep architecture of 
healthy subjects. Indian Journal of Physiology and Pharmacology.48(1): 65-72.

[4] Grandjean, E. 1993. Fatique Dalam : Parmeggiani, L.ed Encyclopedia of Occupational Health and Safety. Third (Revised) edt. Geneva: International Labour Organization.

[5] Heo, Y. S., S. J. Chang, S. G. Park, J. H. Leem, S. H. Jeon, B. J. Lee, K. Y. Rhee, dan H. C. Kim. 2013. Association between workplace risk factor exposure and sleep disturbance: analysis of the 2nd korean working conditions survey. Annals of Occupational and Enviromental Medicine. 25(41).

[6] Keputusan Menteri Kesehatan Nomor : 1405/Menkes/SK/XI/2002 . 2002. Persyaratan Kesehatan Lingkungan Kerja Perkantoran dan Industri. Jakarta.

[7] Keputusan Menteri Negara Lingkungan Hidup No. 48, 1996. Baku Tingkat Kebisingan Menteri Lingkungan Hidup. Indonesia.

[8] Luxson, M., S. Darlina, dan T. Malaka. 2010. Kebisingan di tempat kerja. Jurnal Kesehatan Bina Husada. 6(2): 75-85.

[9] Melamed S, Rabinowitz S, Feiner M, Weisberg E, Ribak J. 1996. Usefulness of the protection motivation theory in explaining hearing protection device use among male industrial workers. Health Psychology. Morata TC., Fiorini AC, Fischer FM, Krieg EF, Gozzoli L, Colacioppo S. 2001. Factors affecting the use of hearing protectors in a population of printing workers. Noise and Health.

[10] O'Connor, P. J. dan S. D. Youngstedt. 1995. Influence of exercise on human sleep. Exercise and Sport Sciences Reviews. 23(1): 105-134.

[11] Peraturan Menteri Tenaga kerja Dan Transmigrasi Republik Indonesia No. 08 tahun 2010. Alat Pelindung Diri. Jakarta: Departeman Kesehatan RI.

[12] Peraturan Menteri Tenaga Kerja dan Transmigrasi. No. 13 tahun 2011. Nilai Ambang Batas Faktor Fisika dan Kimia di Tempat Kerja. Jakarta: Departeman Kesehatan RI.

[13] Sihar, Tagor. 2005. Kebisingan di Tempat Kerja. Yogyakarta: ANDI.
[14] Tarwaka. Bakri, Solichul. H. A. Sudiajeng, Lilik. Ergonomi Untuk Keselamatan, Kesehatan Kerja dan Produktivitas. Surakarta: Uniba Press, 2004.

[15] Uehli, K., A. J. Mehta, D. Miedinger, K. Hug, C. Schindler, E. H. Trachsler, J. D. Leuppi, dan N. Künzli. 2014. Sleep problems and work injuries: a systematic review and metaanalysis. Sleep Medicine Reviews. 18(1): 61-73. 